\title{
FORMATION, TRANSPORT AND BREAKDOWN OF NEAR-BED HIGH-CONCENTRATED MUD SUSPENSION WITHIN THE NORTH PASSAGE OF THE CHANGJIANG ESTUARY
}

\author{
Jianzhong Ge, SKLEC, East China Normal University, jzge@skec.ecnu.edu.cn \\ Zaiyang Zhou, SKLEC, East China Normal University, zyzhou@163.com \\ Pingxing Ding, SKLEC, East China Normal University, pxding@skec.ecnu.edu.cn
}

\section{INTRODUCTION}

The turbidity maximum region of the Changjiang Estuary would potentially produce near-bed high-concentrated mud suspension (HCMS), which significantly contributes to the sediment transport and morphology within estuary channel. However, the near-bed high-concentrated mud suspension is technologically difficult to be observed and measured in traditional survey methodology. HCMS can frequently occur around an estuary as a result of sediment deposition, mass or bulk erosion, and convergence under physical mechanisms (Bruens et al., 2002; Winterwerp, 2002, 2011).

\section{FIELD INVESTIGATION}

In this work, an integrated tripod system (Fig. 1), mounted with high-resolution up-looking $(50 \mathrm{~cm})$ and down-looking $(5 \mathrm{~cm})$ ADCPs, ALEC for point velocity, RBR for wave measurement, two OBS for turbidity at different heights above the bed, ADV for high-resolution velocity, ASM for 1 -cm-resolution turbidity within 1 meter above the bed. Two tripod systems were deployed on north and south sides of the deep channel to measure the near-bed hydrodynamics and its induced sediment suspension in the middle of the North Passage of the Changjiang Estuary (Fig. 2).

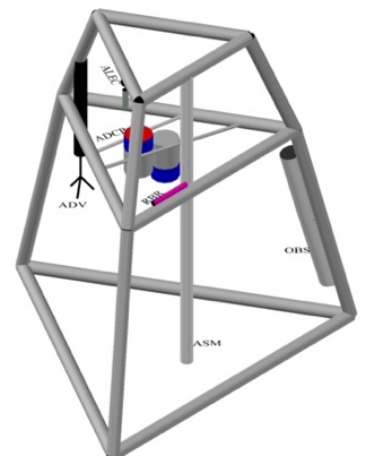

Figure 1 -Sketch of near-bed tripod system

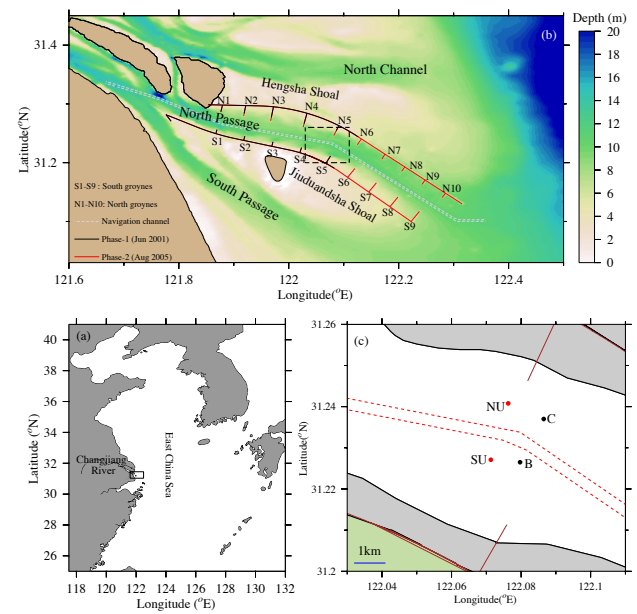

Figure 2 - Survey sites within the North Passage of the Changjiang Estuary, China

\section{RESULTS AND DISCUSSION}

These two tripod systems had detected frequent formation of near-bed HCMS on both sides of deep channel. The OBS and ASM both could quantify the bottom sediment concentration $>15 \mathrm{~g} / \mathrm{L}$, with maximum about $30 \mathrm{~g} / \mathrm{L}$ (Fig. 3). Different patterns for the formation of HCMS are revealed through the monitoring. South tripod found the HCMS were mainly formed during slack-water period in spring tide. The north tripod, however, found the HCMS occurred in whole spring-neap tide cycles during the observation. The frequency of occurrence of HCMS reached $20.9 \%$ at north site. The longest duration of HCMS at both site were about 2.2 hours, which mainly depended on the slack-water's time. The calculated turbulent intensity with ADV indicates the near-bed turbulence at north site is weaker during neap tide cycle than that of south site, which matched the pattern SSC of north site is much higher than that of south site. It indicates higher HCMS could suppress the turbulence, in turn, the weak turbulence significantly increases the accumulation of near-bed HCMS.

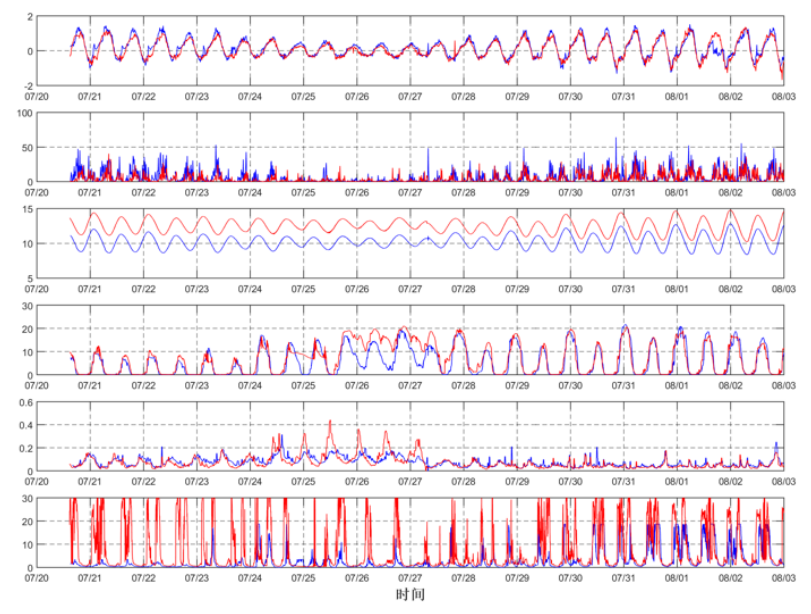

Figure 3 - The timeseries of observed and calculated parameters at south and north sites (from top to bottom: current velocities, turbulent kinetic energy, water depth, salinity, wave height, sediment concentration)

The high-resolution vertical profiles in near-bed 1-meter distance could be interpreted by ASM, indicating strong SSC gradient in the near-bed range with maximum value of $25 \mathrm{~g} / \mathrm{L} / \mathrm{m}$. The residual current and SSC timeseries, by filtering the tide signal out, revealed that strong HCMS occurred during neap tide in the neap tide at the north site. The observation indicates there is a positive feedback loop among HCMS accumulation, turbulence suppression, and enhanced stratification.

The statistics regarding the occurrence of the CBS at sites NU and SU over the entire measurement period were analyzed, and our key findings are illustrated in Fig. 4. The CBS was a common feature for the suspended sediment in the North Passage. At site NU, the CBS 
occurred with a frequency of $20.7 \%$, the maximum SSC of $47.54 \mathrm{~g} / \mathrm{L}$ and the longest duration of $2.83 \mathrm{~h}$. Strong CBS was found during the neap tidal cycle. At site SU, although the mud suspension remained at a lower concentration and CBS occurred with a frequency of only $7.74 \%$, it showed the longest duration of $\sim 2.73 \mathrm{~h}$ (Fig. 4b), which occurred during the spring tidal cycle. This suggests that the CBS was an important contributor to the benthic sediment transport at these sites.

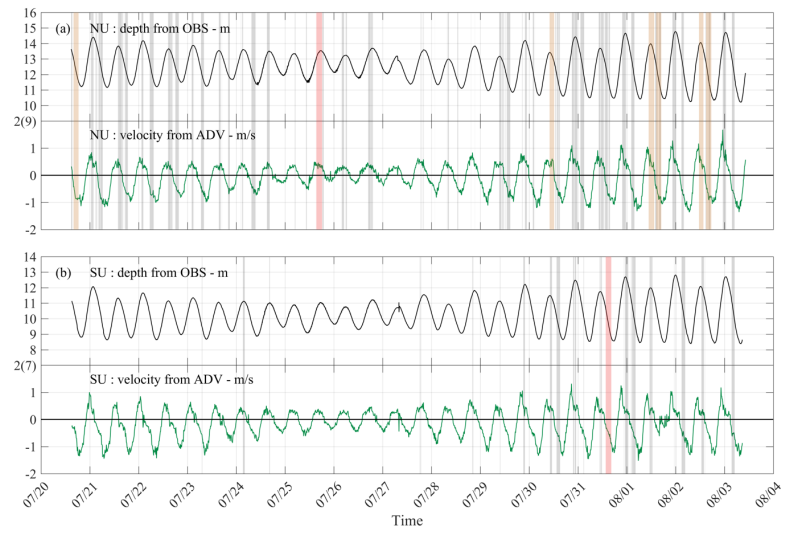

Figure. 4: Time series of depth from OBS and velocity from ADV at NU (a) and SU (b) sites. The pink shading demonstrates the longest occurrence of CBS at these two tripod sites. The yellow shading indicates the occurrence of CBS longer than $2 \mathrm{~h}$. The gray shading shows the occurrence of CBS shorter than $2 \mathrm{~h}$.

The SSC profiles within the 1-m-thickness benthic layer were measured with a 1-cm resolution by the ASM (Fig. $5)$. The whole water column in the 1-m benthic layer was covered by the high sediment suspension with an up-limit concentration of $20 \mathrm{~g} / \mathrm{L}$ at site $\mathrm{NU}$ and of $5 \mathrm{~g} / \mathrm{L}$ at site $\mathrm{SU}$. At site NU, the thickness of CBS was $\sim 60-100 \mathrm{~cm}$ during the tidal transition period of July 20-23. During the neap tidal cycle, with the strong salinity-induced stratification and weak tidal mixing, the thickness of CBS decreased and the vertical gradient of the SSC increased in the bottom benthic layer. The upper 0.6-1.0 mab column was occupied by the sediment with a low concentration of $<8$ $\mathrm{g} / \mathrm{L}$, while in the lower 0-0.4 mab column was featured by the continuous CBS accumulation. With this highresolution AMS profiler, the nearly one-day-lasting CBS was captured around July 25 at site NU (Fig. 5a). During the neap tidal cycle of July $26-28$, the bottom benthic layer was occupied mainly by lower concentration sediment expect for some high-SSC burst events, which was identical to the OBS measurements. During the neap-tospring transition period when the high-SSC burst occurred, the thickness of CBS increased from 0.4 to 1.0 mab.

At site NU, during the spring tidal cycle, the duration of the burst gradually became longer as the tidal velocity increased. At site SU, the main pattern of SSC during the spring tidal cycle was similar to that at site NU, except for low SSC magnitude. However, a different pattern was found during the transition tidal period of July 20-23 and the neap tidal cycle. The water column kept the low SSC during the transition period (Fig. 5b). Significant high-SSC bursts occurred during the neap tidal cycle, with peaks up to the 1.0-mab height and duration up to a few hours. During those bursts, the maximum SSC reached $\sim 18.0$
g/L.

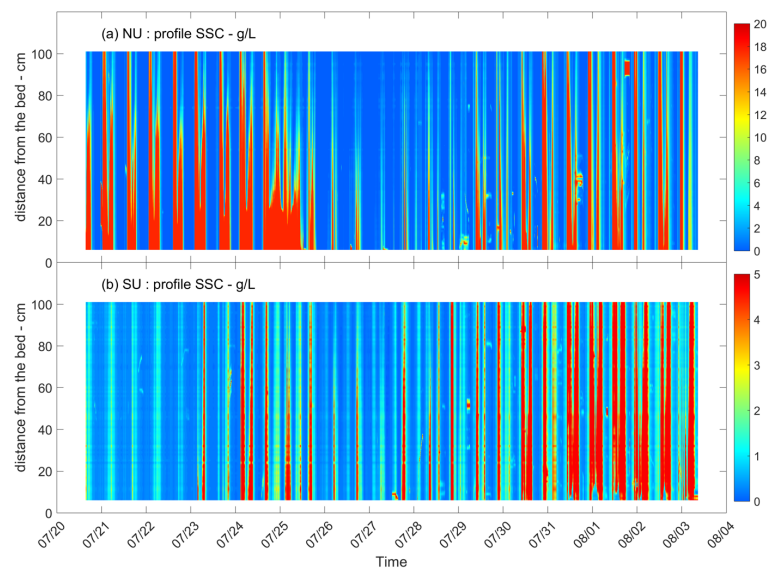

Figure. 5: Variation of SSC in the near-bed 1-m range at NU (a) and SU (b) sites.

A Butterworth filter was used to remove the tidal oscillations from the 2-min-interval sampling of SSC profiles in the near-bed 1-m layer, and then the vertical gradient of SSC was calculated by using the filtered SSC profiles. The vertical gradients of SSC at site NU and site SU are displayed in Fig. 10, which shows that site NU was characterized with a strong SSC gradient, starting from the tidal transient period and raising to a peak during the neap tidal cycle around July $25-26$. The maximum gradient of SSC reached $\sim 40 \mathrm{~g} /\left(\mathrm{L}^{*} \mathrm{~m}\right)$. The vertical gradient of SSC was relatively smaller during the spring tidal cycle (Fig. 10a), with a typical value of 10 $\mathrm{g} /\left(\mathrm{L}^{*} \mathrm{~m}\right)$. For some isolated patches, the gradient was up to $20 \mathrm{~g} /\left(L^{*} \mathrm{~m}\right)$. At site $S U$, the vertical gradient of SSC was generally weak, with a typical value of $2-4 \mathrm{~g} /\left(\mathrm{L}^{*} \mathrm{~m}\right)$ over the neap and spring cycles.

\section{CONCLUSION}

Two tripod systems equipped with multiple state-of-the-art instrument sensors, plus two anchored vessels, were deployed to monitor the benthic concentrated suspension in the North Passage of the Changjiang Estuary. The observed data indicated that the formation of CBS (>15 $\mathrm{g} / \mathrm{L}$ ) was a common feature in the turbidity maximum zone in this region. High frequency CBS occurrence was found at two tripod sites from the late-flood to early-ebb tidal period, especially during the neap tidal cycle. The mean thickness of CBS was about $20-30 \mathrm{~cm}$ above the sea bed. The mechanism of formation of HCMS are examined with high-resolution tripod system, revealing interactions between turbulent kinetics and sediment accumulation.

\section{REFERENCES}

Bruens, Kranenburg and Winterwerp (2002): Physical modelling of entrainment by a Concentrated Benthic Suspension. Proceedings in Marine Science, 5, 109-124. Winterwerp (2002): Scaling parameters for HighConcentrated Mud Suspensions in tidal flow. Proceedings in Marine Science, 5, 171-186.

Winterwerp (2011): Fine sediment transport by tidal asymmetry in the high-concentrated Ems River: indications for a regime shift in response to channel deepening. Ocean Dynamics, 61(2), 203-215. 